\title{
Oral Contraceptive Use in Obese Adolescents: A Cautionary Tale
}

\author{
Vilmarie Rodriguez ${ }^{1}$, Deepti Warad $^{1}$, and Asma Chattha ${ }^{1}$ \\ ${ }^{1}$ Mayo Clinic
}

July 8, 2020

\begin{abstract}
Venous thromboembolism (VTE) is a life-threatening complication rarely encountered with the use of combined oral contraceptives (COCs). Obesity is an additional thrombosis risk factor that has been shown to further increase the risk of VTE with the use of COCs. We present five cases of obese adolescents (BMI $>30 \mathrm{~kg} / \mathrm{m} 2$ ) who encountered thrombosis complications while on COCs. Although the absolute risk of VTE events in the setting of COCs is rare, caution should be observed when choosing hormonal therapy and safer COCs alternatives discussed with adolescents who are obese.
\end{abstract}

\section{Introduction:}

Venous thromboembolism (VTE), is a rare complication seen in women receiving combined oral contraception (COC) containing estrogen and progesterone. The thrombotic risk of COCs is associated with hemostatic alterations, most commonly protein $\mathrm{C}$ resistance (1). Adolescent females have the lowest absolute risk for VTE while receiving COCs when compared to older age groups with an absolute risk for VTE to be less than 1 per 1000 exposure years (1-5). Large population case-control studies report an incidence of VTE in women age category 15-19 years to be 4.2 events per 10,000 exposure years versus 0.7 events per 10,000 years in COC non-users (5).

Despite the small but real increased risk for VTE in female COC users, other thrombosis risk factors such as obesity, further increase VTE risk during COC use $(1-5 ; 11-27)$. We present a case series of five adolescent females with obesity (BMI [?] $30 \mathrm{~kg} / \mathrm{m}^{2}$ ), who developed VTE complications in the setting of COC use. This observation raises the concern of increased thrombosis risk in obese adolescents with COC use and underscores the need to explore safer hormonal alternatives in this patient population.

\section{Results:}

Case 1

A 17 -year-old Caucasian female (BMI $34.09 \mathrm{~kg} / \mathrm{m}^{2}$ ) presented with acute right sided chest pain and shortness of breath. Computed tomography angiography (CTA) of the chest revealed bilateral pulmonary embolism (PE) (Figure 1). Ultrasound Doppler evaluation of the lower extremities did not show any evidence of a DVT. Echocardiogram evaluation did not show evidence of cor pulmonale. Risk factors for VTE were obesity and the use of COC (norgestrel $0.3 \mathrm{mg}$ - ethinyl estradiol $30 \mathrm{mcg}$ ) for approximately one year, prescribed to treat dysmenorrhea and menorrhagia. Thrombophilia evaluation was negative. Repeat chest CTA after three months of anticoagulation showed resolution of the bilateral pulmonary embolism.

\section{Case 2}

A 17-year-old Caucasian female (BMI $32.5 \mathrm{~kg} / \mathrm{m}^{2}$ ) presented with worsening headaches associated with vomiting for 2 weeks. Head magnetic resonance venography (MRV) revealed right dural, transverse and sigmoid sinus venous thrombosis (Figure 2 and $2 \mathrm{~b}$ ). Patient reported the use of COC for 2 years (norethindrone $1 \mathrm{mg}$ -ethinyl estradiol $35 \mathrm{mcg}$ ) prescribed for the management of menorrhagia. Anticoagulation with Apixaban 
was continued for a total duration of 6 months with repeat MRV showing residual non-occlusive residual thrombosis in the right transverse and sigmoid sinuses. Thrombophilia evaluation did not reveal congenital or acquired abnormalities.

\section{Case 3}

A 14-year-old Caucasian female (BMI $31.3 \mathrm{~kg} / \mathrm{m}^{2}$ ) presented with a two week duration of bilateral chest pain and shortness of breath. Chest CTA was performed that revealed bilateral PE (see Figure 3). Ultrasound evaluation of the lower extremities did not reveal DVT. Echocardiogram showed no evidence of cor pulmonale. Thrombophilia evaluation was negative. She had been taking norgestimate-ethinyl estradiol ( $0.25 \mathrm{mg}-35 \mathrm{mcg})$ for 3 months to regulate her menstrual periods. Patient received Enoxaparin for 3 months, with repeat CTA showing residual thrombosis at the bifurcation of the descending right pulmonary artery. Recommendations were made to continue therapeutic anticoagulation for an additional three months and to reassess thrombus resolution with repeat chest CTA.

\section{Case 4}

A 15-year-old female (BMI $39.73 \mathrm{~kg} / \mathrm{m}^{2}$ ), presented with sudden onset of shortness of breath and chest pain resulting in a syncopal episode. Patient had history of acne treated with isotretinoin and COC (norgestimate $0.25 \mathrm{mg}$ - ethinyl estradiol $35 \mathrm{mcg}$ ) for 5 months Chest CTA evaluation revealed saddle pulmonary embolism (Figure 4a and $4 \mathrm{~b}$ ). Echocardiogram showed moderate to severe right ventricular enlargement with severe decrease in systolic function. Due to severity of PE with cardiovascular compromise, systemic thrombolysis with tissue plasminogen activator (tPA) was initiated at $0.05 \mathrm{mg} / \mathrm{kg} / \mathrm{hr}$ along with unfractionated heparin at 10 units $/ \mathrm{kg} / \mathrm{hr}$. Continuous dose tPA was discontinued and a bolus of tPA at $0.5 \mathrm{mg} / \mathrm{kg}$ given over $2 \mathrm{hr}$ due to worsening hypotension. Patient cardiovascular condition improved and repeat chest CTA revealed decreased clot burden in the pulmonary arteries. Patient completed 3 months of oral anticoagulation with Rivaroxaban. Repeat echocardiogram and CTA showed normalization of her right ventricular systolic function and PE respectively.

Thrombophilia testing after completion of anticoagulation revealed slightly elevated fibrinogen $(585 \mathrm{mg} / \mathrm{dL}$; reference range 200-500 mg/dL) with an elevated D-dimer (789 ng/mL; reference range [?] $500 \mathrm{ng} / \mathrm{mL}$ ). Patient was encouraged to lose weight and will continue close follow up due to concern of recurrent thrombosis in the setting of elevated D-dimers.

\section{Case 5}

An 11-year-old Caucasian female with trisomy 21 (BMI $34.7 \mathrm{~kg} / \mathrm{m}^{2}$ ), hypothyroidism on thyroid hormone replacement therapy, required placement of a etonogestrel implant in addition to COC (norgestimate 0.25 $\mathrm{mg}$ - ethinyl estradiol $35 \mathrm{mcg}$ ) for the management of menorrhagia. Ten months after initiation of hormonal therapy, patient presented with sudden onset of right leg swelling and pain. Ultrasound Doppler evaluation revealed extensive thrombosis throughout the right common femoral vein, femoral vein and upper popliteal vein (Figure 5). Unfractionated heparin was initiated. Due to patient's developmental delay and inability to keep her on strict bed rest during catheter directed thrombolysis it was decided to transitioned patient to Apixaban. Patient showed clinical and radiological improvement one month following initiation of anticoagulation.

\section{Discussion}

Obesity defined as a body mass index [?] $30 \mathrm{~kg} / \mathrm{m}^{2}$ has been found to affect $38.3 \%$ of US women between the years of 2011-2014 (6). It is predicted that obesity will affect nearly one in two adults by 2030 with higher than $50 \%$ prevalence in 29 states, particularly among women (7). Similar statistical predictions exist for pediatric and adolescent age groups. Between the decades of 1980-2012, obesity has more than doubled in children aged 6-11 years (7\% to 18\%) and quadrupled in adolescents aged $12-19$ (5\% to $21 \%$ ) (6). With growing rates of obesity in pediatric and adolescent population, more adolescent girls with weight abnormalities (overweight or obese) are seeking the use of COC to treat several of the gynecological and 
non-gynecological conditions. Primary care providers and gynecologists often face the concern of weighing the risk of VTE risk with COC use in the setting of obesity.

Although several studies have demonstrated the relationship of VTE risk associated with obesity and COC use, data in adolescent population are limited as most studies include adult women of child-bearing age in their analyses. A case-control study among users of low dose estrogen $(<50 \mathrm{mcg})$ combined COC, was conducted among women ages 15-44. The adjusted odds ratio (OR) for VTE associated with current COC use was 4.07 (95\% CI: 2.77-6.0). The OR was higher for obese women than for non-obese $(\mathrm{p}=0.01)$ and was found nearly as doubled in those [?] $30 \mathrm{~kg} / \mathrm{m}^{2}$ compared to [?] $30 \mathrm{~kg} / \mathrm{m}^{2}$ (11). In a systematic review of cardiovascular complications among obese COC users, obese women had 5 to 8 times greater risk for cardiovascular events including myocardial infarction, stroke and VTE compared to non-obese non-COC users and 10 times that of non-obese COC users. Five prospective cohort studies were identified in this systematic review as indirect evidence, all of which supported increased risk for VTE as BMI increased, suggesting a dose-response relationship between BMI and risk for VTE (12). Other studies have similarly confirmed an increased risk for VTE in obese COC users reporting an OR from 5.2 to 7.8 compared with that of obese women who did not use COC (13-15). In a retrospective study of 26 young women (ages 12-21 years) with COC related VTE, $96 \%$ of the patients had at least one VTE risk factor and $42 \%$ with two or more, with obesity being the most common additional risk factor (50\%) (16).

Several hemostatic abnormalities have been observed in obesity such as altered fibrinolysis, increased plasminogen activator inhibitor (PAI-1), increased platelet aggregability through elevations of von Willebrand factor and higher levels of fibrinogen, factors VII and VIII (8-10). Estrogen via nuclear estrogen receptors and progestins (e.g. desogestrel) also affect plasma concentration of clotting factors such as elevated factors II, VII, VIII, X, fibrinogen and decreased antithrombin (17). As a consequence, these coagulation abnormalities can synergistically increase the risk for VTE complications in obese patients on COC therapy. Congenital thrombophilia risk factors such as factor V Leiden have also been demonstrated to increase the absolute risk for thrombosis with COC use (18). However, no underlying thrombophilia risk factors were noted in our patients.

Despite the reported increased risk of VTE in association with COC use and obesity, some groups such as the European Expert Panel recommend contraception "to all women regardless of their weight" considering the need to reduce unintended pregnancy and its associated risk for VTE. The risk of VTE is higher during pregnancy and the postpartum period with an adjusted hazard ratio 16.0 versus 2.2 during COC use $(19,20)$. Other experts recommend the use of low risk COC with second-generation progestin and lowest estrogen dose in women less than 35 years while women with risk factors for thrombosis such as age $>35$ years and obesity, should not use high risk products and primarily consider progestin only COC and be cautious about use of low dose COC (21-23). Second-generation products (norgestrel, levonorgestrel) confer about half the risk for VTE in contrast to third- or fourth-generation products such as desogestrel, gestodene, or drospirenone, cyproterone acetate (21-23). Combined products with 30-40 mcg of estrogen have $20 \%$ higher risk for VTE than $20 \mathrm{mcg}$ of estrogen with the same dose and type of progestin (21). Transdermal patches and vaginal rings belong to the high-risk products. Progestin only pills, levonorgestrel intrauterine device and implants do not confer increased risk for VTE (21-23).

The World Health Organization (WHO) and the Center for Disease Control (CDC) provide grade 2 recommendations regarding the use of COC (the advantages generally outweigh the risks) while the United Kingdom Medical Eligibility Criteria (UKMEC) state grade 2 recommendations for those with a BMI $<35$ $\mathrm{kg} / \mathrm{m}^{2}$; grade 3 for those with a BMI $35-39 \mathrm{~kg} / \mathrm{m}^{2}$ (the risk usually outweigh the advantages: use not usually recommended unless no alternatives are available and grade 4 for BMI [?] $40 \mathrm{~kg} / \mathrm{m}^{2}$ (the condition represents an unacceptable health risk if the contraceptive method is used; method not to be used) (24-26).

All of our patients had a BMI in the obese category and they encountered VTE complications in the setting of COC use. Although the overall expert opinion is to exercise caution with the use of COC in the setting of obesity, there is need to heighten clinician awareness of the increased risk of VTE complications and choose safer alternatives when prescribing hormonal therapy to adolescents girls with the rising global prevalence 
of obesity.

\section{References}

1. Tans G, Bouma BN, Büller HR, Rosing J. Changes of hemostatic variables during oral contraceptive use. Semin Vasc Med 2003; 3 (1): 61-68.

2. O'Brien SH. Contraception-Related Venous Thromboembolism in Adolescents. Semin Thromb Hemost 2014; 40: 66-71.

3. Lidegaard O, Nielsen LH, Skovlund CW, Løkkegaard E. Venous thrombosis in users of non-oral hormonal contraception: follow up study, Denmark 2001-10. BMJ 2012; 344: e2990.

4. Lidegaard O, Nielsen LH, Skovlund CW, Skjeldestad FE, Løkkegaard E. Risk of venous thromboembolism from use of oral contraceptives containing different progestogens and estrogen doses: Danish cohort study 2001-9 BMJ 2011; 343: d6423.

5. Jick SS, Kaye JA, Russman S, Jick H. Risk of nonfatal venous thromboembolism with oral contraceptives containing norgestimate or desogestrel compared with oral contraceptives containing levonorgestrel. Contraception 2006; 73 (6): 566-70.

6. Ogden CL, Carroll ED, Fryar CD et al. Prevalence of obesity among adults and youth United States 2011-2014: NCHS Data Brief 2015; (219): 1-8.

7. Ward Z, Bleich SN, Cradock AL, Barrett JL et al. Projected U.S State-Level Prevalence of Adult Obesity and Severe Obesity. N Engl J Med 2019; 381: 2440-2450.

8. Pannaciulli N, DeMitrio V, Marino R et al. Effect of glucose tolerance status on PAI-1 plasma levels in overweight and obese subjects. Obes Res 2002; 10: 17-25.

9. Juhar-Vague I, Alessi MC, Mauri A et al. Plasminogen activator inhibitor-1, inflammation, obesity, insulin resistance and vascular risk. J Thromb Haemost 2003; 1: 1575-1579.

10. Mertens I, Van Gall LF. Obesity, haemostasis and the fibrinolytic system. Obes Rev 2002; 3: 85-101.

11. Sydney S, Petitti DB, Soff GA et al. Venous thromboembolic disease in users of low-estrogen combined estrogen-progestin oral contraceptives. Contraception. 2004; 70: 3-10.

12. Horton LG, Simmons KB, Curtis KM. Combined hormonal contraceptive use among obese women and risk for cardiovascular events; A systematic review. Contraception 2016; 94: 590-604.

13. Abdollahi M, Cushman M, Roseendal FR. Obesity: risk of venous thrombosis and the interaction with coagulation factor levels and oral contraceptive use. Thromb Haemost 2003; 89: 493.

14. Pomp ER, LeCessie S, Rosendaal FR et al. Risk of venous thrombosis: obesity and its joint effect with oral contraceptive use as prothrombotic mutations. Br J Haematol 2007; 139: 289-296.

15. Lidegaard O, Kreiner S. Contraceptives and cerebral thrombosis: a five year national case-control study. Contraception 2002; 65 (3): 197-205.

16. Pillai P, Bonny AE, O'Brien SH. Contraception-related venous thromboembolism in a Pediatric Institution. J Pediatr Adolesc Gynecol 2013; 26: 186-188.

17. Conard J. Biological coagulation findings in third-generation oral contraceptives. Hum Reprod Update . 1999;5(6):672-680.

18. Jeanet M. Kemmeren, Ale Algra, Joost C. M. Meijers, Guido Tans, Bonno N. Bouma, Joyce Curvers, Jan Rosing, Diederick E. Grobbee; Effect of second- and third-generation oral contraceptives on the protein $\mathrm{C}$ system in the absence or presence of the factor $\mathrm{V}_{\text {Leiden }}$ mutation: a randomized trial. Blood 2004; 103 (3): 927-933.

19. Merki-Feld GS, Skouby S, Serfaty D et al. European Society of contraception Statement on contraception in obese women. Eu J Contracept Reprod Health Care 2015; 20: 19-28.

20. Van Vlijmen EF, Veeger NJ, Middeldorp S et al. Thrombotic risk during oral contraceptive use and pregnancy in women with Factor V Leiden or prothrombin mutation: a rational approach to contraception. Blood 2011; 118 (8): 2055-2061.

21. Lidegaard O. Hormonal contraception, thrombosis and age. Expert Opin Drug Saf 2014; 13 (10): 13531360 .

22. Gronich N, Lavi I, Rennert G. Higher risk of venous thrombosis associated with drospirenone-containing oral contraceptives: a population-based cohort study. CMAJ . 2011;183(18):E1319-E1325. 
23. Dragoman MV, Tepper NK, Fu R, Curtis KM, Chou R, Gaffield ME. A systematic review and metaanalysis of venous thrombosis risk among users of combined oral contraception. Int J Gynaecol Obstet. 2018;141(3):287-294.

24. World Health Organization Medical Eligibility Criteria for Contraceptive Use. Geneva, Switzerland: World Health Organization: 2009.

25. Faculty of Sexual \& Reproductive Health-Care. UK medical eligibility for contraceptive use. Available at www. Ffprhc.org.uk/admin/uploads/UKMEC 2009.pdf. Accessed December 23, 2019.

26. Division of Reproductive Health, National Center for Chronic Disease Prevention and Health Promotion: Centers for Disease Control and Prevention; Farr S, Folger SG, Paulen M, et al. US medical eligibility criteria for contraceptive use, 2010: adapted from the World Health Organization Medical Eligibility Criteria for Contraceptive Use, $4^{\text {th }}$ ed. MMWR Recomm Rep 2010; 59 (RR-4). 1-86.

\section{Figures}

\section{Figure 1}

Case 1: Pulmonary emboli within segmental and subsegmental branches pulmonary arteries of the mid lungs bilaterally.

Figure 2a and 2b:

Case 2: Coronal and sagittal views MRV showing thrombosis in the transverse and sagittal sinuses respectively.

\section{Figure 3:}

Case 3: Bilateral pulmonary emboli.

\section{Figure $4 \mathrm{a}$ and $4 \mathrm{~b}$ :}

Case 4: Saddle pulmonary embolism involving main pulmonary arteries bilaterally (sagittal and crosssectional views)

Figure 5

Case 5: Venous mapping illustrating thrombosis extending from right common femoral, femoral and popliteal vein.

\section{Hosted file}

Figures.docx available at https://authorea.com/users/340833/articles/467896-oralcontraceptive-use-in-obese-adolescents-a-cautionary-tale 